\title{
Fostering Work Ability Among Menopausal Women. Does Any Work-Related Psychosocial Factor Help?
}

This article was published in the following Dove Press journal: International Journal of Women's Health

\section{Sara Viotti \\ Gloria Guidetti \\ Daniela Converso (D) \\ Ilaria Sottimano}

Department of Psychology, University of Turin, Turin, Italy
Correspondence: Gloria Guidetti Via Verdi 10, Turin 10124, Italy Email gloria.guidetti@gmail.com
Introduction: Due to the aging workforce, it will become even more common for organizations to count, among their employees, women who are dealing with menopause. To date, no knowledge is available regarding the work ability among menopausal women. With this view, the aim of the present study was to identify work-related psychosocial factors associated with work ability in a sample of menopausal working women.

Methods: A self-report questionnaire was administered to 1069 menopausal women employed as administrative officers in the Italian public sector. The study design was crosssectional.

Results: Work ability was found to be negatively associated with family-work conflict $(\beta=-0.21$, $p=0.0001)$ and positively associated with health-oriented organizational climate $(\beta=0.12, p=$ $0.0001)$, job autonomy $(\beta=0.08, p=0.006)$, and skill discretion $(\beta=0.08, p=0.048)$. Conversely, work ability did not show significant associations with job demands, flexible working hours, and social support.

Discussion: From a practical point of view, our study identifies various areas of intervention that could foster job sustainability during menopause. In particular, our findings suggest that, to improve women's job sustainability across their entire work-life span, it may be crucial to develop organizational policies, training, and activities specifically dedicated to sustaining menopausal women's well-being.

Keywords: work ability, menopause, aging workforce, women, work-related psychosocial factors

\section{Introduction}

The aging of the workforce, as well as the increasing number of working women, has resulted in a growing interest in the link between the topics of menopause and work. $^{1,2}$ In Europe, employment rates for older workers (aged 55-64) have increased by nearly $10 \%$ in the decade from 2000 to $2010 ;^{3}$ moreover, the number of over- 65 workers is expected to increase by $20 \%$ by $2020 .^{4}$ In 2000 , the employment rate of older women (aged 55-64) was 27.4\%. In 2010, the rate increased to $38.8 \%$. ${ }^{4}$ Given these statistics, it will become even more common for organizations to count, among their employees, women who are dealing with menopause. ${ }^{5}$

Menopause is a complex physiological process that marks the end to the reproductive phase of a woman's life. ${ }^{6}$ Typical examples of menopausal symptoms are hot flashes, sleep disturbances, decreased physical strength, mood changes, or bladder irritability. Those symptoms may vary in terms of incidence and intensity across 
women and along the various phases of the menopausal process (ie, pre-, peri-, or post-menopausal periods ${ }^{7}$ ). The literature has highlighted that menopause negatively affects the quality of a woman's life, lessening the general levels of subjective well-being. ${ }^{8}$ Furthermore, previous studies have demonstrated that, during and after the menopausal transition, women's quality of life in the workplace might be significantly undermined. ${ }^{9}$ Some studies, finding a strong and negative association between menopausal symptoms and ability to work, ${ }^{10}$ suggested that work ability might play a central role in preventing a decrease of the jobrelated quality of life during menopause. Even if the directionality of this relationship has not been ascertained, it is plausible to hypothesize that the influence between these two elements is reciprocal. On one hand, poor work ability might intensify menopausal symptoms; on the other hand, the arrival of menopausal symptoms might hamper ability to work, thus leading to further negative outcomes. In fact, reduced work ability was found to predict work-related exhaustion, intention to leave, absenteeism, and reduced job performance across various working populations, including older workers and disabled workers. ${ }^{11,12}$ work ability is a central indicator of job sustainability, referring to the physical and intellectual resources on which workers can rely to meet the demands posed by their work. ${ }^{13}$ According to the WHO's health perspective, work ability is a capital in which workers and their organizations may invest to achieve positive future outcomes. ${ }^{14}$ Despite the importance of promoting job sustainability throughout the entire work-life span, ${ }^{15}$ to date, no knowledge is available regarding the work-related psychosocial factors affecting work ability among menopausal women. Previous studies mostly focused on identifying the work-related predictors of work ability among aging workers. ${ }^{16}$ For instance, a study conducted in a sample of female preschool teachers found that in the age cohort 35-44, work ability was significantly predicted by support from colleagues; by contrast, in the age cohort $45-54$, work ability was found to be associated with reward and skill discretion, and in the age cohort 55-63, it was sustained by meaning of work. ${ }^{17} \mathrm{~A}$ number of studies also examined the the work ability of workers reporting chronic diseases. ${ }^{18,19}$ Among them, a recent systematic review of studies focused on workers with various type of disease (ie, mental disorders, cardiovascular diseases, and cancers) has highlighted the centrality of the work-related psychosocial factors (including job control and work ability) in predicting return to work. ${ }^{20}$ Overall, this corpus of studies has demonstrated that psychosocial factors that sustain work ability may be different across the lifespan and that workers with transitory or permanent health impairment might need specific attention in the workplace to preserve their work ability. The lack of a specific focus on menopause has impeded the identification of the psychosocial factors and the proper interventions in the workplace specifically dedicated to protecting work ability among women who deal with this physiological transition. Considering the increasing number of aging working women, the identification of specific measures to support menopausal women and their work ability appears to be urgent in order to prevent negative outcomes for both workers and their organization, such as reduced job well-being and premature job abandonment.

To contribute to fill this gap, the aim of the present study was to identify work-related psychosocial factors affecting work ability in a sample of menopausal women employed as administrative officers in the Italian public sector.

\section{The Relationship Between Work-Related Psychosocial Factors and work ability}

Based on previous literature, ${ }^{21}$ we included, in the present study, the following work-related psychosocial factors, in order to test their association with work ability: job demands, job autonomy, skill discretion, social support, family-work conflict, and organizational support for health reasons.

Job demands, job control, and social support are identified as playing a central role in affecting job well-being by the job demand-control-support (JDCS) model, ${ }^{22}$ which is one of the most important and well-documented models in the literature. According to this model, job demands refers to the extent to which the tasks require workers to expend sustained effort in carrying out their duties. The two job control aspects, skill discretion and decision authority, express the extent to which workers can control their tasks and general work activities. Skill discretion refers to the opportunity to use specific job skills in the work process, while decision authority refers to the extent to which a worker has autonomy in making task-related decisions. Regarding social support, Karasek and Theorell ${ }^{23}$ identified two main sources that concern the "overall levels of helpful social interaction available on the job from co-workers and supervisors." The predicting role of these three orders of factors on work ability was largely demonstrated in several studies carried out in a wide range of working populations. ${ }^{24}$ Although there are no previous studies examining the predictive role of these psychosocial factors on work ability among menopausal women, there is evidence that suggests 
the significance of these associations. Bariola et $\mathrm{al}^{25}$ found, in a sample of higher education teachers, a significant association between menopausal symptoms and both job autonomy and social support. Hardy et $\mathrm{al}^{2}$ found that job demands negatively impacted job well-being in a sample of women employed in the public sector. Similarly, Evolahti ${ }^{26}$ ascertained that experiencing control at work was significantly related to reduced cardiovascular disease risk among perimenopausal women.

To account for the specific aspects potentially relevant to fostering work ability among menopausal women, we also consider a factor assessing the work-private life balance and two aspects reflecting organizational support for health balance. Regarding the balance between work and private life, the present study has chosen to focus on the negative interference of private life on the work domain. ${ }^{27}$ Previous studies observed that women have a significantly lower work ability, if compared to their male counterparts, ${ }^{16}$ explaining these differences with the persistence of the gender imbalance in domestic work. According to Roterbeng et $\mathrm{al}^{28}$ women experience a double work burden resulting from their simultaneous engagement in paid employment plus a greater part or complete responsibility for the domestic load. The risk of experiencing family-work conflict among middle-aged women may be even greater because, at this stage of life, in addition to health issues related to menopause, women may be engaged in activities in the domestic domain, such as taking care of older or disabled members of the family (eg, parents). ${ }^{28}$

Regarding organizational support for health reasons, the present paper considered two factors, ie, flexible working hours and health-oriented organization climate. According to Gragnano et $\mathrm{al}^{29}$ the first refers to the cognitive appraisal of how much the job permits boundary modification and integration in favor of the health domain. The second refers to the perception of the top management's attention to employee health. From an empirical point of view, flexible working hours were found to significantly affect job well-being among menopausal women. ${ }^{2,25}$ Flexible working hours may help preserve work ability by giving menopausal women the opportunity to dedicate time to take care of their general health and manage menopausal symptoms (eg, having time for medical checkups, avoiding exposure to excessive stress by taking a day off when necessary). ${ }^{2,25}$ No previous studies specifically focused on the association between organizational support for health reasons and work ability among menopausal women; however, a work environment that supports a work-health balance was found to represent a positive condition for workers dealing with health issues. ${ }^{20,29}$

\section{Materials and Methods Participants and Data Collection}

With an agreement between the Municipality of Turin and the Department of Psychology at the University of Turin, a survey aimed at assessing work-related stress and well-being among workers employed at the Municipality of Turin was carried out. In December 2017, a self-report questionnaire was sent to the institutional e-mails of all the administrative employees of the Municipality of Turin. The questionnaire included a section specifically dedicated to examining job well-being and job sustainability during menopause. A question stating "are you in menopause?" (response: "yes/no") was used to identify menopausal women and to invite them to fill out the additional section in the questionnaire. In order to help women respond correctly and to minimize the risk of including "false positives," the abovementioned question was accompanied by the following statement "While responding, please consider that menopause is diagnosed when a woman has gone without a menstrual period for 12 consecutive months."

Of the 9531 questionnaires sent, 3026 were returned correctly filled out. Of those, 1069 respondents declared that they were menopausal women. They were aged $56.24(\mathrm{sd}=6.32$, $\min =38, \max =66$ ), and they had been in menopause, on average, for 6.32 years $(\mathrm{sd}=4.55, \min =1, \max =26)$. They were all administrative officers with a permanent contract.

The survey was intended to fulfill a legal obligation regarding the assessment of wok-related stress risk (Law 81/08). The research protocol was developed following the National Institute Against Workplace Accidents (INAIL) guidelines concerning "The methodology for the assessment and management of work-related stress risk" (developed in compliance with Italian Law 81/2008 on safety and health at work). ${ }^{30}$ Because the survey was carried out to fulfill a legal obligation, no ethical approval was required (no reference to ethical board approval appear either in the INAIL guideline or Law 81/08). However, the research protocol was developed in accordance with Italian Law 101/2018 on workplace privacy and conformed to the provisions of the Declaration of Helsinki in 1964 (as revised in Fortaleza, 2013), and all ethical guidelines were followed as required for conducting human research. The questionnaire was covered by a letter that openly described the research purposes, the anonymity of the data collection and treatment. The cover letter clearly 
stated the voluntary nature of participation and that questionnaire returns implied consent. In particular, the research group, in accordance with the organizational stakeholders of the public organization involved (ie, unions, worker representatives, top management, equal opportunity guarantee committee), decided not to ask workers to sign consent forms, to ensure unconditional anonymity of the data collection. In practice, the collection of the signed consent forms would have resulted in a list of the names of the workers who did (and did not) choose to participate in the survey. Even if the risks to violating worker privacy could be minimized by adopting proper measures to ensure anonymity (eg, by covering the information under professional secrecy), the involved stakeholders agreed to prevent this risk by avoiding creating any tracks regarding the identity of the workers who participated in the survey.

\section{Measures}

The questionnaire was developed specifically for this study (Appendix 1). It included scales measuring the outcome variables, independent variables, and control variables.

\section{Outcome Variable}

work ability was measured with the work ability index (WAI), ${ }^{11}$ which contains seven sections, each of which gives a partial score that contributes to form the overall work ability score (range: 7-49). The seven sections measure: (1) current work ability compared with lifetime best (range: 1-10); (2) work ability in relation to mental and physical demands (range: 2-10); (3) number of current diseases diagnosed by a physician (range: 1-7); (4) estimated work impairment due to diseases (range: 1-6); (5) sick leave during the past 12 months (range: 1-5); (6) selfprognosis of work ability for the next two years; and (7) mental resources (range: 1-4).

\section{Independent Variables}

Job demands (three items, eg, "I am required to work excessively"), job autonomy (three items, eg, "My job allows me to make a lot of decisions on my own"), skill discretion (five items, eg, "My job requires that I learn new things"), support from colleagues (six items, eg, "People at work are helpful in getting the job done"), and support from superiors (four items, eg, "My supervisor is concerned about the welfare of those under him/her") were measured using subscales from the Job Content Questionnaire $\left(\mathrm{JCQ}^{31}\right)$. The scales employed a four-point response range from 0 (strongly disagree) to 3 (strongly agree). Familywork conflict was measured using six items (eg, "You have difficulty in concentrating on the job because of worries about domestic matters") on a scale from the Work-Home Interaction Survey Nijmegen $\left(\mathrm{SWING}^{27}\right)$, with a four-point scale of responses ranging from 1 (never) to 4 (always). Health-oriented organizational climate and flexible working hours for health reasons were measured with five items (eg, "The health of the staff is a priority for the organization") and six items (eg, "There is no flexibility in your schedule, not even for health issues"), respectively, taken from the Work-Health Balance Questionnaire. ${ }^{29}$ On both scales, responses were given on a five-point scale ranging from 1 (strongly disagree) to 5 (strongly agree).

\section{Control Variables}

Age, duration of the menopause status, and resilience were included in the study as control variables. Age was considered because it is well-established that age and work abilityk are inversely correlated. ${ }^{32}$ Duration of menopause was included as a control variable as previous studies have demonstrated that, throughout the menopausal transition and after, the symptomatology changes considerably both in terms of intensity and type of symptoms experienced. ${ }^{6}$ Moreover, a previous study found a significant effect of this variable on ability to work. ${ }^{10}$

In addition, resilience was considered a potential confounder in the relationship between work-related psychosocial factors and work ability among menopausal women. Resilience is a personal resource reflecting positive psychological capacity for coping and adjusting behaviors in the face of significant adversity or risk. ${ }^{33}$ A previous study demonstrated that a high level of personal resources may predict work ability measured 10 years later. ${ }^{12}$ In the present study, resilience (eg, "At work, I am able to adapt to any change required by the situation") was measured by a nine-item scale developed by Campbell-Sills et al. ${ }^{33,34}$ Responses on these scales were given on a fivepoint scale with a range of 1 (not true) to 5 (completely true).

\section{Statistical Analyses}

All the analyses were conducted using SPSS 25.

To explore the univariate relationships among the study variables, the preliminary analyses included Pearson's correlations.

A multivariate linear regression (method: Enter) was performed to identify the significant correlates of work ability 


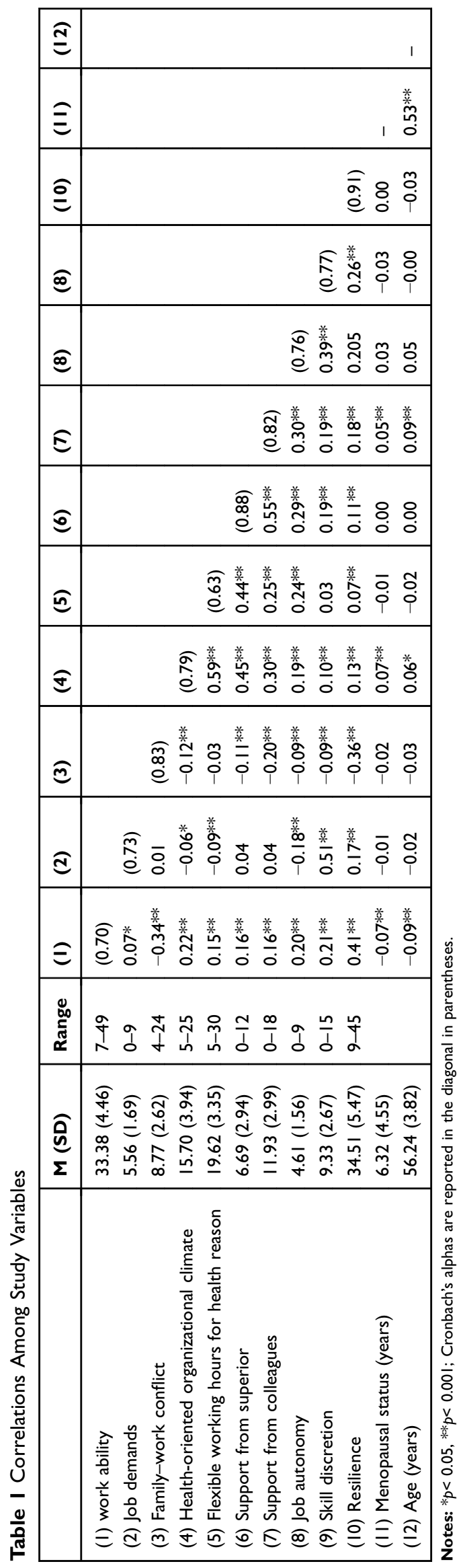

among the work-related psychosocial factors considered (ie, job demands, family-work conflict, health-related organizational climate, flexible working hours, support from superiors, support from colleagues, skill discretion, and job autonomy). Specifically, in Step 1, the work-related psychosocial factors were entered. In Step 2, the control variables were added (ie, age, duration of menopausal status, and resilience).

\section{Results}

\section{Correlations}

Table 1 reports the results of the Pearson's correlations among the variables under study. work ability was found to be positively associated with job demands $\left(0.07^{*}\right)$ and negatively with family-work conflict $\left(-0.34^{* *}\right)$. On the other hand, work ability showed a positive correlation with healthoriented organizational climate $\left(0.22^{* *}\right)$, flexible working hours for health reasons $\left(0.15^{* *}\right)$, support from peers $\left(0.16^{* *}\right)$ and superiors $\left(0.16^{* *}\right)$, skill discretion $\left(0.21^{* *}\right)$, job autonomy $\left(0.20^{* *}\right)$, and resilience $\left(0.41^{* *}\right)$, and age $\left(-0.09^{* *}\right)$. work ability did not report a significant association with duration of the menopausal transition.

\section{Multiple Linear Regression}

Table 2 reports the results of the multiple regression analyses. The tolerance index (1/VIF) indicated that there were no signs of multicollinearity in any of the regression models carried out, because, for each independent variable included in the regression, the values fell between 0.79 and 0.94 (less than 0.20 indicates potential issues ${ }^{35}$ ). At Step 1, the overall amount of variance explained was $19 \%$. work abilityk was found to be negatively associated with family-work conflict ( $\beta=-0.30, p=0.0001)$. Conversely, work ability was positively associated with health-oriented organizational climate $(\beta=0.12, p=0.0001)$, job autonomy $(\beta=0.09, p=0.002)$, and skill discretion $(\beta=0.13, p=$ $0.0001)$. At Step 2 , after adding the control variables, the amount of variance explained reached $27 \%\left(\Delta R^{2}=0.080\right.$, $F=38.60, p=0.0001$ ). No change, in terms of significance and direction, was observed regarding the association between the major study variables factors (factors associated to significant $\beta$ values: family-work conflict, healthoriented organizational climate, job autonomy, and skill discretion). Regarding control variables, resilience $(\beta=$ $0.28, p=0.0001)$, and age $(\beta=-0.08, p=0.007)$ were significantly associated with work ability, while the duration of the menopausal status was not. 
Table 2 Multiple Linear Regression (Dependent Variable: work ability)

\begin{tabular}{|c|c|c|c|c|c|c|c|c|c|c|}
\hline & \multicolumn{5}{|c|}{ Step I } & \multicolumn{5}{|c|}{ Step 2} \\
\hline & B & Std. Error & Beta & $\mathbf{t}$ & $\mathbf{p}$ & B & Std. Error & Beta & $\mathbf{t}$ & $\mathbf{p}$ \\
\hline Constant & 31.10 & 1.10 & & 28.10 & 0.0001 & 29.40 & 2.40 & & 12.24 & 0.0001 \\
\hline Job demands & 0.02 & 0.08 & 0.00 & 0.23 & 0.816 & -0.05 & 0.08 & -0.01 & -0.60 & 0.543 \\
\hline Family-work conflict & -0.52 & 0.04 & -0.30 & -10.82 & 0.0001 & -0.37 & 0.04 & -0.21 & -7.57 & $0.000 \mathrm{I}$ \\
\hline Health-oriented organizational climate & 0.72 & 0.20 & 0.12 & 3.53 & 0.0001 & 0.73 & 0.19 & 0.12 & 3.70 & 0.0001 \\
\hline Flexible working hours for health reasons & 0.38 & 0.29 & 0.04 & 1.31 & 0.190 & 0.22 & 0.27 & 0.02 & 0.79 & 0.428 \\
\hline Support from superior & -0.01 & 0.05 & -0.01 & -0.21 & 0.829 & 0.00 & 0.05 & 0.00 & -0.11 & 0.906 \\
\hline Support from colleagues & 0.00 & 0.05 & 0.001 & 0.03 & 0.974 & 0.00 & 0.04 & 0.00 & -0.11 & 0.908 \\
\hline Job autonomy & 0.27 & 0.09 & 0.09 & 3.04 & 0.002 & 0.23 & 0.08 & 0.08 & 2.75 & 0.006 \\
\hline Skill discretion & 0.21 & 0.05 & 0.13 & 3.72 & 0.0001 & 0.13 & 0.05 & 0.08 & 2.44 & 0.048 \\
\hline Resilience & & & & & & 0.23 & 0.02 & 0.28 & 9.66 & 0.0001 \\
\hline Duration of menopausal status (years) & & & & & & -0.04 & 0.03 & -0.04 & -1.40 & 0.160 \\
\hline Age (years) & & & & & & -0.09 & 0.03 & -0.08 & -2.68 & 0.007 \\
\hline
\end{tabular}

Notes: $R^{2}$ step $I=0.19, F=31.21, p=0.0001 ; R^{2}$ step $2=0.27, F=35.66, p=0.0001 . \Delta R^{2}=0.080, F=38.60, p=0.0001$.

\section{Discussion}

The aim of the present study was to identify work-related psychosocial factors affecting work abilityk in a sample of menopausal women working as administrative officers in an Italian public administration.

According to multiple regression analysis, the factor with the strongest association with work ability was family-work conflict. This is in accordance with the results of an ISTAT survey, ${ }^{36}$ which revealed that, in Italy, $75 \%$ of the domestic work in dual-earner families is carried out by women. The present study enhances this knowledge by highlighting that, during menopause, the negative interference of women's private domain on their work domain represents a central risk factor that may contribute to depleted work ability. Future studies should be aimed at understanding which are the specific aspects of women's private lives (eg, personal health issues, aged parent care) that negatively interfere with work and contribute to hampering work ability.

Both skill discretion and job autonomy, which, according to Karasek, ${ }^{22}$ represent the two sides of job control, were found to be positively associated with work ability. This finding is in line with a previous study by Evolahti et $\mathrm{al}^{26}$ who found that job control was significantly associated with better cardiovascular health among menopausal women. A possible explanation regarding why job control represents a key resource for menopausal women is that it may help them better manage the boundary between their private and work domains during this delicate stage of their lifespan. ${ }^{29}$ For instance, discretion in the work organization may favor the management of the reciprocal interference between health issues and work demands. Another possible explanation is that autonomy and skill discretion are characteristics that reflect the prestige of a job. As suggested by Morris and Symonds, ${ }^{37}$ during menopausal transition, women may deal with identity crises due to physical transformations and changes in their family role. In this context, a high social status and authoritative job position may favor the maintenance of self-efficacy and self-esteem during this transition, thus contributing to preserving work ability.

The last factor found to be significant was health-oriented organizational climate, indicating that a higher attention to employee health by top management is associated with higher levels of work ability among menopausal women. These results confirmed previous studies that have highlighted the organizational climate as a crucial factor to sustain the adjustment between personal needs and job duties throughout the various phases of the menopausal transition. ${ }^{21}$ In particular, a positive social climate in which women feel comfortable expressing any need or problem, related to menopause or health in general, may help preserve work ability by preventing the development of potential incompatibilities between health and work.

\section{Limitations}

The present study has some limitations. The most important is the cross-sectional design. Future research should employ multiple waves to ascertain that the work-related psychosocial factors (family-work interference, skill discretion, job autonomy, and health-oriented organizational climate) predict work ability and not vice versa. 
Moreover, the use of a nonrandomized sample represents a limiting factor for this study. Therefore, caution should be exercised when generalizing the results to other administrative workers of the Italian public sector.

Another limitation is that menopausal status has been collected using a self-reported method and was not ascertained through an assessment carried out by a physician. In addition, the research protocol did not include any tool to measure menopausal symptoms, thus impeding controlling for the result for the severity of the symptoms associated to the menopausal status.

Future studies may benefit from employing research designs that use data from multiple sources (eg, the inclusion of a medical assessment for menopausal symptoms) and include scales to assess the severity of menopausal symptoms (eg, MENQOL ${ }^{38}$ ).

\section{Practical Implications}

While it is increasingly more common to find menopausal women in the workplace, little is known concerning the aspects of their psychosocial work environment that make the job sustainable at this stage of life. ${ }^{39}$

The main contribution of the present study is the identification of family-work conflict, skill discretion, job autonomy, and health-oriented organizational climate as significant correlates of menopausal women's work ability. In light of these findings, our study suggests various areas of intervention that could potentially improve job sustainability at this stage of the working life. Our findings suggest that menopausal women's work ability may benefit from an organizational climate in which employee health needs are taken into great consideration. Therefore, the development of organizational training, policies, and activities, specifically dedicated to menopause, may be crucial to improve women's job sustainability across their entire work-life span. Examples in this direction are information campaigns that may contribute to generating a more positive cultural environment toward the specific topic of menopause at work. Health promotion programs should include information about menopause, aging, and health to help women adopt healthier lifestyles (eg, diet change, stress management, development of positive attitudes toward aging and menopause). ${ }^{21}$ Moreover, any specific organizational policies and interventions on work environment (e.g., job design, ergonomic adjustments) to sustain menopausal women's quality of work life should be developed, adopting a participative design process that actively involves menopausal women and encourages them to express their needs and identify the critical aspects of their work environment in relation to their status and possible solutions.

An important risk factor for menopausal women's work ability is the interference between private life and work domain. This finding confirms the previous literature that highlights that female workers experience a "double work burden" resulting from their simultaneous engagement in paid employment plus a greater share or complete responsibility for the domestic load. ${ }^{28,36}$ Given these findings, informative campaigns aimed at promoting cultural change regarding the strong imbalance between the domestic role of genders, to the disadvantage of women, would be crucial. $^{28}$ Moreover, organizational welfare should offer integrative health insurance tailored for older workers that covers expenses for health services not provided by national health services, both for workers and family members (eg, prompt medical checkups, eldercare facilities for older or disabled parents).

Finally, previous literature has mainly focused on health management and social support as the possible psychosocial aspects to consider in relation to menopausal women's quality of work life. ${ }^{21}$ The present study highlighted that a challenging job, characterized by high levels of skill discretion and job autonomy, may contribute to helping women preserve their work ability during menopause. In this regard, to enhance work ability and job motivation, organizations should implement career development plans that take into account life, health, and career need changes throughout the entire work-life span.

\section{Funding}

Title of the project: "Work and Menopause", funders: University of Turin, Department of Psychology, Local research, B line (PI: Sara Viotti). Award number: VIOS_RILO_18_01.

\section{Disclosure}

Dr Gloria Guidetti reports grants from University of Turin during the conduct of the study. The authors report no conflicts of interest in this work.

\section{References}

1. Griffiths A, Ceausu I, Depypere H, et al. EMAS recommendations for conditions in the workplace for menopausal women. Maturitas. 2016;85:79-81. doi:10.1016/j.maturitas.2015.12.005

2. Hardy C, Thorne E, Griffiths A, Hunter MS. Work outcomes in midlife women: the impact of menopause, work stress and working environment. Women Midlife Health. 2018;4(1):3. doi:10.1186/ s40695-018-0036-z 
3. Özdemir E, Ward T, Fuchs M, et al. Employment of Older Workers. Research Note No. 5/2015. Brussels: European Commission; 2015.

4. Eurostat. European Union Labour force survey - annual results. 2016. Available from: http://ec.europa.eu/eurostat/statisticsexplained/index. php/Labour_market_and_Labour_force_survey_(LFS)_statistics. Accessed February 27, 2020.

5. Nelson HD. Menopause. Lancet. 2008;371:760-770. doi:10.1016/ S0140-6736(08)60346-3

6. Mishra G, Kuh D. Perceived change in quality of life during the menopause. Soc Sci Med. 2006;62(1):93-102. doi:10.1016/j. socscimed.2005.05.015

7. Moilanen J, Aalto AM, Hemminki E, Aro AR, Raitanen J, Luoto R. Prevalence of menopause symptoms and their association with lifestyle among Finnish middle-aged women. Maturitas. 2010;67 (4):368-374. doi:10.1016/j.maturitas.2010.08.007

8. Dennerstein L, Lehert P, Guthrie J. The effects of the menopausal transition and biopsychosocial factors on well-being. Arch Women's Ment Health. 2002;5(1):15-22. doi:10.1007/s007370200018

9. Fenton A, Panay P. Menopause and the workplace. Climacteric. 2014;17(4):317-318. doi:10.3109/13697137.2014.932072

10. Geukes M, Van Aalst MP, Robroek SJ, Laven JS, Oosterhof H. The impact of menopause on work ability in women with severe menopausal symptoms. Maturitas. 2016;90:3-8. doi:10.1016/j. maturitas.2016.05.001

11. McGonagle AK, Fisher GG, Barnes-Farrell JL, Grosch JW. Individual and work factors related to perceived work ability and labor force outcomes. J Appl Psychol. 2015;100(2):376-398. doi:10.1037/a0037974

12. Viotti S, Guidetti G, Loera B, Martini M, Sottimano I, Converso D. Stress, work ability, and an aging workforce: a study among women aged 50 and over. Int $J$ Stress Manag. 2017;24(S1):98-121. doi:10.1037/str0000031

13. Tuomi K, Ilmarinen J, Jahkola A, Katajarinne L, Tulkki A. Work Ability Index. Helsinki: Institute of Occupational Health; 1994.

14. Airila A, Hakanen JJ, Schaufeli WB, Luukkonen R, Punakallio A, Lusa S. Are job and personal resources associated with work ability 10 years later? The mediating role of work engagement. Work Stress. 2014;28(1):87-105. doi:10.1080/02678373.2013.872208

15. Eurofound. Sustainable Work Throughout the Life Course: National Policies and Strategies. Luxembourg: Publications Office of the European Union; 2016. Available from: https://www.dataplan.info/ img_upload/5c84ed46aa0abfec4ac40610dde11285/ef1610en_2.pdf. Accessed April 18, 2020.

16. Camerino D, Conway PM, Van der Heijden BIJM, et al. Low-perceived work ability, ageing and intention to leave nursing: a comparison among 10 European countries. Int J Stress Manag. 2006;56(5):542-552. doi:10.1111/j.1365-2648.2006.04046.x

17. Sottimano I, Viotti S, Guidetti G, Converso D. Protective factors for work ability in preschool teachers. Occup Med. 2017;67(4):301-304. doi:10.1093/occmed/kqx031

18. Rashid M, Kristofferzon ML, Heiden M, Nilsson A. Factors related to work ability and well-being among women on sick leave due to long-term pain in the neck/shoulders and/or back: a cross-sectional study. BMC Public Health. 2018;18(1):672. doi:10.1186/s12889-0185580-9

19. van der Doef MP, Schelvis RMC. Relations between psychosocial job characteristics and work ability in employees with chronic headaches. J Occup Rehabil. 2019;29:119-127. doi:10.1007/s10926-018-9769-7

20. Gragnano A, Negrini A, Miglioretti M, Corbière M. Common psychosocial factors predicting return to work after common mental disorders, cardiovascular diseases, and cancers: a review of reviews supporting a cross-disease approach. J Occup Rehabil. 2018;28 (2):215-231. doi:10.1007/s10926-017-9714-1

21. Jack G, Riach K, Bariola E, Pitts M, Schapper J, Sarrel P. Menopause in the workplace: what employers should be doing. Maturitas. 2016;85:88-95. doi:10.1016/j.maturitas.2015.12.006
22. Karasek R, Brisson C, Kawakami N, Houtman I, Bongers P, Amick B. The Job Content Questionnaire (JCQ): an instrument for internationally comparative assessments of psychosocial job characteristics. J Occup Health Psychol. 1998;3(4):322-355. doi:10.1037/1076-8998.3.4.322

23. Karasek RA, Theorell T. Healthy Work: Stress Productivity, and the Reconstruction of Working Life. New York (NY): Basic Books; 1990.

24. Van den Berg TIJ, Elders LAM, De Zwart BCH, et al. The effects of work-related and individual factors on the work ability index: a systematic review. Occup Environ Med. 2008;66:211-220. doi:10.1136/oem.2008.039883

25. Bariola E, Jack G, Pitts M, Riach K, Sarrel P. Employment conditions and work-related stressors are associated with menopausal symptom reporting among perimenopausal and postmenopausal women. Menopause. 2017;24:247-251. doi:10.1097/GME.000000000000 0751

26. Evolahti A, Hultcrantz M, Collins A. Psychosocial work environment and lifestyle as related to lipid profiles in perimenopausal women. Climacteric. 2009;12(2):131-145. doi:10.1080/13697130802521290

27. Geurts SA, Taris TW, Kompier MA, Dikkers JS, Van Hooff ML, Kinnunen UM. Work-home interaction from a work psychological perspective: development and validation of a new questionnaire, the SWING. Work Stress. 2005;19(4):319-339. doi:10.1080/026783 70500410208

28. Rotenberg L, Portela LF, Banks B, Griep RH, Fischer FM, Landsbergis P. A gender approach to work ability and its relationship to professional and domestic work hours among nursing personnel. Appl Ergon. 2008;39(5):646-652. doi:10.1016/j.apergo.2008.02.013

29. Gragnano A, Miglioretti M, Frings-Dresen MHW, de Boer AG. Adjustment between work demands and health needs: development of the work-health balance questionnaire. Rehabil Psychol. 2017;62 (3):374-386. doi:10.1037/rep0000121

30. National Institute for Insurance against Accidents at Work (INAIL). The Methodology for the Assessment and Management of WorkRelated Stress Risk. Milan: INAIL; 2018. Available from: https:// www.inail.it/cs/internet/docs/alg-the-methodology-for-theassessment.pdf. Accessed February 27, 2020.

31. Karasek RA. Job Content Instrument Questionnaire and User's Guide, Version 1.1. Los Angeles (CA): University of Southern California; 1985.

32. Ilmarinen J, Tuomi K, Klockars M. Changes in the work ability of active employees over an 11-year period. Scand J Work Environ Health. 1997;23(1):49-57.

33. Campbell-Sills L, Stein MB. Psychometric analysis and refinement of the Connor-Davidson Resilience Scale (CD-RISC): validation of a 10-item measure of resilience. J Trauma Stress. 2007;20 (6):1019-1028. doi:10.1002/jts.20271

34. Di Sipio A, Falco A, Kravina L, De Carlo NA. Positive personal resources and organizational well-being: resilience, hope, optimism, and self-efficacy in an Italian health care setting. TPM Test Psychom Methodol Appl Psychol. 2012;19(2):81-95.

35. Field A. Discover Statistics Using SPSS. 3th ed. London: Sage; 2009.

36. Italian Institute of Statistic (ISTAT). Lavoro e conciliazione dei tempi di vita. 2013. Available from: https://www.istat.it/it/files/2013/03/3 lavoro-conciliazione.pdf. Access February 27, 2020.

37. Morris ME, Symonds A. 'We've been trained to put up with it': real women and the menopause. Crit Public Health. 2004;14(3):311-323. doi:10.1080/09581590400004436

38. Kopenhager T, Guidozzi F. Working women and the menopause. Climacteric. 2015;18(3):372-375. doi:10.3109/13697137.2015.102 0483

39. Lewis JE, Hilditch JR, Wong CJ. Further psychometric property development of the menopause-specific quality of life questionnaire and development of a modified version, MENQOL-intervention questionnaire. Maturitas. 2005;50(3):209-221. doi:10.1016/j. maturitas.2004.06.015 


\section{Publish your work in this journal}

The International Journal of Women's Health is an international, peerreviewed open-access journal publishing original research, reports, editorials, reviews and commentaries on all aspects of women's healthcare including gynecology, obstetrics, and breast cancer. The manuscript management system is completely online and includes a very quick and fair peer-review system, which is all easy to use. Visit http://www.dovepress.com/testimonials.php to read real quotes from published authors. 